\title{
The Bdtf1 Gene in Alternaria brassicicola Is Important in Detoxifying Brassinin and Maintaining Virulence on Brassica Species
}

\author{
Akhil Srivastava, ${ }^{1}$ II Kyu Cho, ${ }^{2}$ and Yangrae $\mathrm{Cho}^{1,3}$ \\ ${ }^{1}$ Plant and Environmental Protection Sciences, University of Hawaii at Manoa, 3190 Maile Way, St. John 317, Honolulu, HI \\ 96822, U.S.A.; ${ }^{2}$ Korea Bio-Safety Institute, Co., LTD., 362-20 Seongju-ro, Gamgok, Eumseong, Chungbuk 369-850, South \\ Korea; ${ }^{3}$ Korea Research Institute of Bioscience and Biotechnology, 30 Yeongudanji-ro, Ochang, Cheongwon, Chungbuk \\ 363-883, South Korea
}

Submitted 1 July 2013. Accepted 8 August 2013.

\begin{abstract}
Brassinin is an antifungal compound induced in Brassica plants after microbial infection. Molecular evidence is incomplete, however, in supporting the importance of brassinin in plant resistance to pathogens. To test the importance of brassinin in plant defense, we studied the functions of the gene Bdtf1 in the necrotrophic fungus Alternaria brassicicola. Several strains of mutants of this gene were weakly virulent on Brassica species, causing lesions $70 \%$ smaller in diameter than the wild type on three Brassica species. These mutants, however, were as virulent as the wild type on Arabidopsis thaliana. They were similar to the wild type in spore germination, colony morphology, and mycelial growth in nutrient-rich media, both with and without stress-inducing chemicals. Unlike wild-type $A$. brassicicola, however, the mutants failed to germinate and their hyphal growth was arrested in the presence of $200 \mu \mathrm{M}$ brassinin. When grown in a medium containing $100 \mu \mathrm{M}$ brassinin, wild-type mycelium entirely converted the brassinin into a nontoxic derivative, of which the precise chemical nature was not established. Mutants of the $B d t f 1$ gene were unable to perform this conversion. Our results support the hypothesis that the ability of $A$. brassicicola to detoxify brassinin is necessary for successful infection of Brassica species.
\end{abstract}

Brassica species contribute substantially to the global production of food, oil, and fodder, as well as biofuel. For example, brown mustard (Brassica juncea var. oleifera) and canola (B. napus, Brassica campestris, or Brassica rapa var. rapa) are economically important oilseed plants, and green cabbage and cauliflower (B. oleracea) are important table vegetables. Despite multiple, complex defense systems, including the induction of phytoalexins, Brassica species are susceptible to black spot disease caused by Alternaria brassicicola (Vishwanath et al. 1999). Currently, cultivars of Brassica species resistant to A. brassicicola are not commercially available.

Plants generally protect themselves from attack by potential pathogens. Recent research in molecular plant-pathogen interac-

Corresponding author: Yangrae Cho; Telephone: +1.808 .956 .5305 ; E-mail: yangrae@ hawaii.edu or yangraec@kribb.re.kr

* The $\boldsymbol{e}$-Xtra logo stands for "electronic extra" and indicates that two supplementary figures are published online.

(C) 2013 The American Phytopathological Society tions identified a layer of defenses that start with recognition of microbe-associated molecular patterns (MAMPs). This recognition leads to signal transduction and a MAMP-triggered resistance or immunity (Boller and Felix 2009; Jones and Dangl 2006). Plant resistance mechanisms include the production of antimicrobial compounds known as phytoalexins, which are an important part of the defense repertoire (Hammerschmidt 1999; Zhou et al. 1999). MAMPs that induce phytoalexins include the fungal toxin victorin (Tada et al. 2005), fungal chitin (Okazaki et al. 2004), and bacterial flagellin or glycoprotein (Gust et al. 2007; Millet et al. 2010) among others (Ahuja et al. 2012). Phytoalexins are also induced by necrotrophic fungi. For example, indolyl phytoalexins are induced in Brassica spp. by both $A$. brassicicola and Botrytis cinerea (Govrin and Levine 2002; Pedras et al. 2009b). Phytoalexins in Brassica spp., however, are insufficient to suppress lesion development or parasitic growth of these successful necrotrophic pathogens.

To date, 44 phytoalexins have been identified in the Brassicaceae, or crucifer, family (Pedras et al. 2011a). Camalexin, the phytoalexin produced by Arabidopsis thaliana, confers partial resistance to fungal pathogens (Glazebrook and Ausubel 1994). It induces programmed cell death of the necrotrophic fungus Botrytis cinerea (Shlezinger et al. 2011) and also disrupts the cell membrane of the bacterium Pseudomonas syringae (Rogers et al. 1996). Alternaria brassicicola colonizes the camalexin-deficient pad3 mutant more extensively than it colonizes wild-type Arabidopsis thaliana (Glazebrook et al. 1996; Zhou et al. 1999). Brassinin is produced by many Brassica species and may affect cell-membrane integrity and melanin accumulation of $A$. brassicicola (Joubert et al. 2011; Sellam et al. 2007b).

Brassinin and its derivatives (hereafter called brassinins) are synthesized de novo in Brassica species when challenged by microbes, such as the fungal pathogen A. brassicicola or the bacterial pathogen Pseudomonas cichorii (Pedras et al. 2009b; Takasugi et al. 1986). Brassinin has antifungal activities against A. brassicicola in vitro (Sellam et al. 2007a). However, it is quickly modified and neutralized during plant infection by wildtype A. brassicicola, producing the intermediate metabolites $\mathrm{N}^{\prime}$-indolylmethanamine and $\mathrm{N}^{\prime}$-acetyl-3-indolylmethanamine (Pedras et al. 2011a). This finding suggests that detoxification of brassinins by A. brassicicola is important for pathogenicity. However, studies on the effects of brassinins on pathogen mutants that are either unable to detoxify or inefficiently detoxify brassinins are unavailable to directly support this speculation. The aim of this study was to identify a gene essential to the detoxification of brassinins and to investigate the importance of 
brassinin detoxification in the successful infection of Brassica species by $A$. brassicicola. In this study, we describe a gene that is important for the germination and vegetative growth of A. brassicicola in the presence of brassinin. Loss-of-function mutants of the gene showed a severe reduction in virulence. This study demonstrates the need of this fungus to detoxify brassinin for successful infection.

\section{RESULTS}

\section{Bdtf1 gene.}

We previously generated targeted gene-disruption mutants for over 200 genes that encode putative transcription factors with at least one $\mathrm{C}_{2} \mathrm{H}_{2}$-zinc finger domain. Among these genes, we reported mutants of 139 genes, including seven genes associated with pathogenesis (Cho et al. 2009, 2012; Srivastava et al. 2012). Since the year 2010, we have produced deletion mutants of 33 new genes that encode fungal-specific transcription factors. We previously reported that mutants of one of these 33 genes, designated $A b P f 2$, is nonpathogenic but otherwise shows no aberrant morphological phenotype (Cho et al. 2013). We identified another gene of which the mutants were morphologically indistinguishable from the wild type but were significantly less virulent than the wild-type $A$. brassicicola. This gene was predicted to encode 808 amino acids. It included a GAL4 $\left(\mathrm{Zn}_{2} \mathrm{Cys}_{6}\right)$ fungal-specific DNA binding domain (IPR001138,
PF00172) predicted by Interpro (Bateman et al. 2004) and a nuclear localization signal predicted by PSORT (Horton and Nakai 1997). A copy of a homologous, probably orthologous, gene $(E$ value $=0)$ is present in eight members of class Dothideomycetes. The whole-genome sequences of these fungi are publicly available at the National Center for Biotechnology Information (NCBI) website. Homologs of the gene were annotated as either a hypothetical protein or a $\mathrm{C} 6$ zinc-finger domain protein in other fungal genomes. We named this gene Brassinin detoxification factor 1 (Bdtfl).

\section{Generation of $\Delta b d t f 1$ mutants.}

We produced seven strains of $\Delta b d t f l$ mutants with the $B d t f l$ codig region replaced by a single copy of the hygromycin $\mathrm{B}$ transferase $(H y g B)$ resistance-gene cassette (Fig. 1A). We also produced six strains of $\Delta b d t f l$ mutants by replacing the coding region with a single copy of a gene encoding green fluorescent protein (GFP) and a $H y g B$ resistance-gene cassette (GFP$H y g B)$ (Fig. 1B).

\section{Reduced virulence on Brassica plants.}

Biological assays were initially performed on green cabbage (Brassica oleracea). The virulence of three strains of the Bdtfl mutant, $\Delta b d t f 1-5, \Delta b d t f 1-9$, and $\Delta b d t f 1-12$, was compared with that of wild-type $A$. brassicicola. Lesions produced by these mutant strains were approximately $70 \%$ smaller in diameter
A
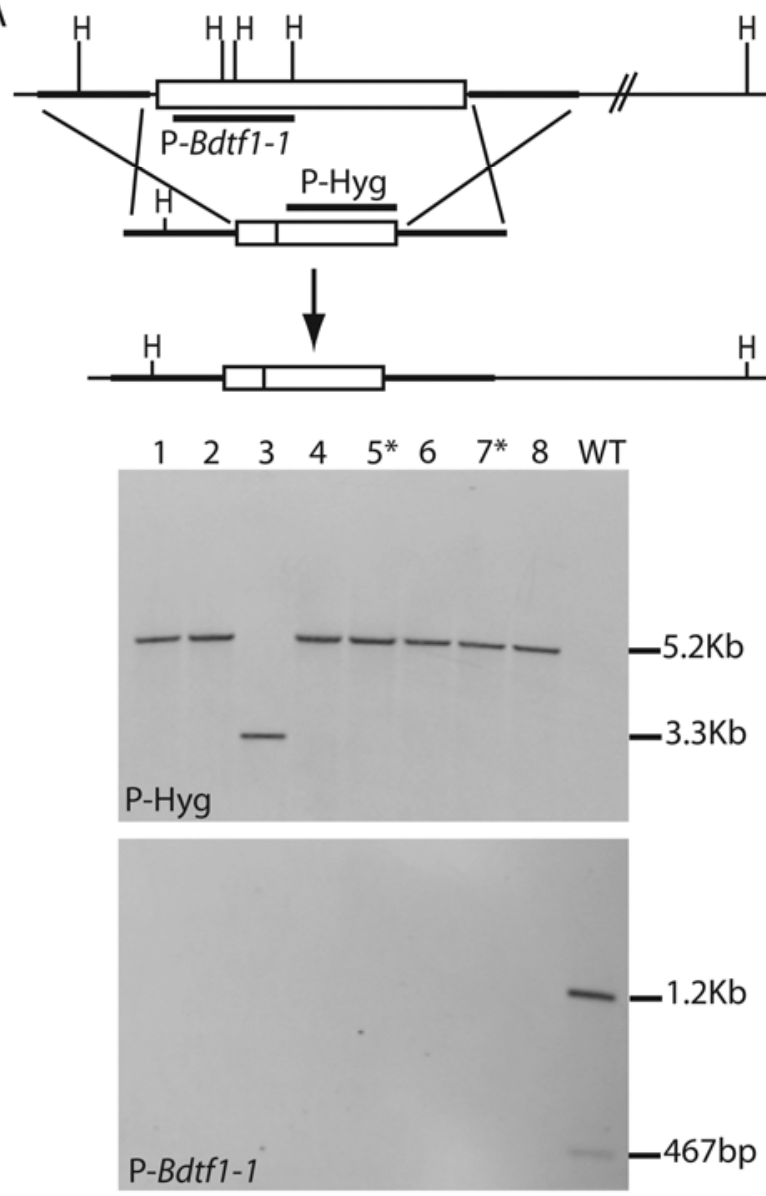

B
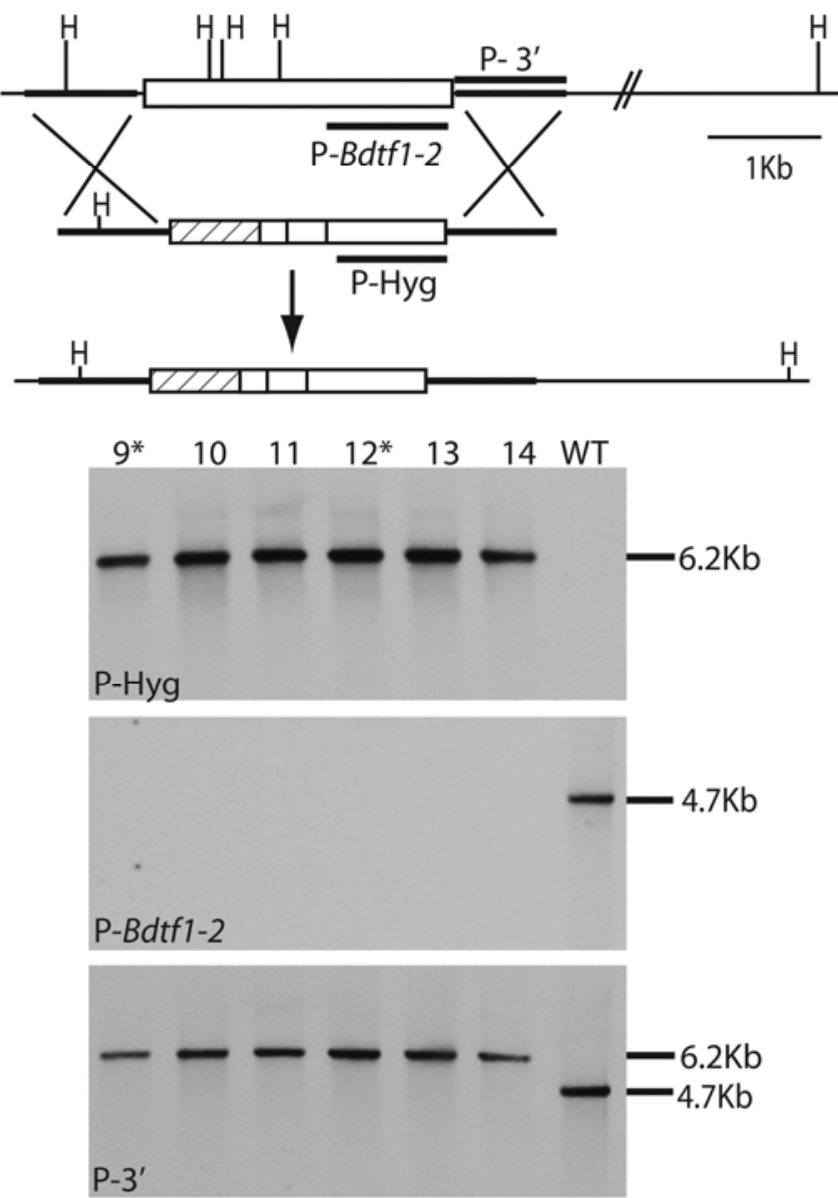

Fig. 1. Targeted deletion of the Bdtfl gene. A, Replacement of the Bdtfl coding region with the selectable marker hygromycin B transferase (HygB) resistance gene cassette. B, Replacement of the Bdtfl coding region with a green fluorescent protein coding region (hatched box) plus a $H y g B$ resistancegene cassette. In both A and B, the upper panel is a schematic diagram of the wild-type locus, replacement construct, and mutant locus, in order. The lower panel is a collection of Southern blots showing loss of the Bdtfl gene in selected mutants. Boxes and thick lines represent coding regions and flanking regions, respectively. Asterisks (*) indicate DNA lanes of mutants whose pathogenicity assay results are presented in this study. Probe regions are marked by P-Bdtf1-1, P-Bdtf1-2, P-3', and P-Hyg. H = HindIII enzyme digestion site. 
than those produced by wild-type $A$. brassicicola (Fig. 2A to C; Table 1). We used $\Delta b d t f 1-5$ and $\Delta b d t f 1-9$ strains for further virulence assays on five additional cultivars from three Brassica species. Both strains consistently produced lesions 72 to $89 \%$ smaller than the wild type on all plants tested (Fig. 2E to $\mathrm{H}$; Table 2). To confirm that the reduced virulence was due to the deletion of the $B d t f l$ gene, the $\Delta b d t f l-5$ strain was complemented with the wild-type allele of the $B d t f l$-coding gene ( $\Delta b d t f 1: B d t f 1)$. The complemented mutant produced lesions comparable to wild-type $A$. brassicicola, indicating that its virulence on cabbage had been restored (Fig. 2C; Table 1).

\section{Virulence on wounded cabbage leaves.}

Physical injury makes living plant tissue vulnerable to invasion by most pathogens. This includes nonpathogenic mutants, such as the A. brassicicola mutants $\Delta a b s t e 12$ and $\Delta a b n i k 1$ (Cho et al. 2009). These mutants failed to cause lesions on healthy plant tissue but were able to colonize wounded cabbage leaves. In contrast, the wounding of Arabidopsis thaliana triggers powerful but transient protection against Botrytis cinerea strains that are susceptible to a phytoalexin, camalexin (Chassot et al. 2008). We tested whether the $\Delta b d t f l$ mutants would be more virulent on wounded than on nonwounded host tissue. When the $\Delta b d t f l$ mutants were inoculated on wounded leaves, they still produced lesions $62 \%$ smaller than the wild type (Fig. 2D; Table 1).

\section{Unchanged virulence on Arabidopsis thaliana.}

We tested the virulence of the $\Delta b d t f 1-5$ and $\Delta b d t f 1-9$ strains on Arabidopsis thaliana ecotype Col-0 and its pad3 mutants. When $5 \times 10^{5}$ conidia per milliliter of the $\Delta b d t f 1$ mutant, the complemented mutant ( $\Delta b d t f 1: B d t f 1)$ or wild-type $A$. brassicicola were spray-inoculated on Arabidopsis thaliana, disease severity, as measured by the number of lesions and dead leaves, was similar (Fig. 2I to K; Table 3). Spot-inoculation of 2,000 conidia of either $\Delta b d t f 1-5$ or wild-type A. brassicicola in $10 \mu \mathrm{l}$
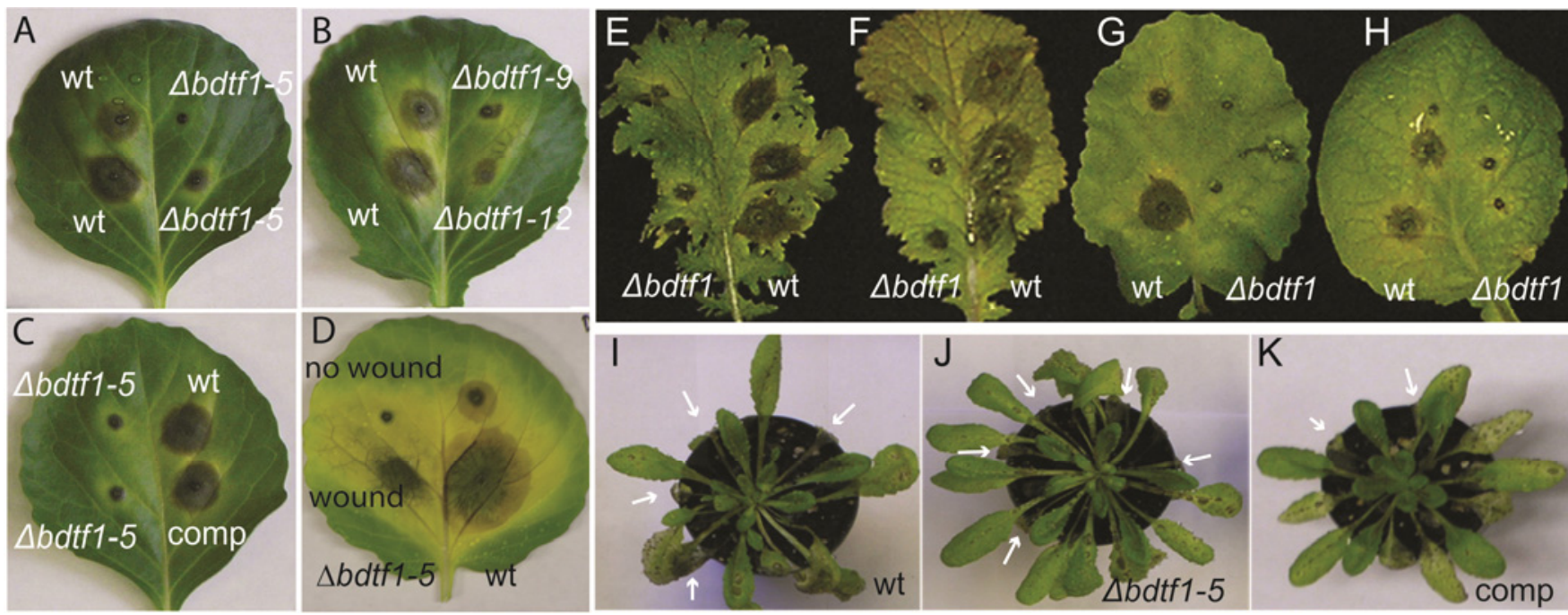

Fig. 2. Reduced virulence of mutants on Brassica species but not on Arabidopsis thaliana. A and $\mathbf{B}$, Lesions caused by three strains of $\Delta b d t f l$ mutants and wild-type Alternaria brassicicola on leaves of green cabbage, Brassica oleracea. C, Results of complementation of a $\Delta b d t f 1-5$ mutant with the wild-type allele. D, Lesions on mechanically wounded tissues of B. oleracea. E, Lesions on green mustard 'Pizzo' (B. juncea). F, Lesions on green mustard 'Homiz' (B. juncea). G, Lesions on cauliflower (B. oleracea var. botrytis). H, Lesions on broccoli (B. oleracea). I to K, Similar disease severity caused by wild-type A. brassicicola, the $\Delta b d t f 1-5$ mutant, and its complemented mutant on spray-inoculated wild-type Arabidopsis thaliana (Col-0). Arrows point to dead leaves. $\mathrm{wt}=$ wild-type A. brassicicola $; \Delta b d t f 1=B d t f 1$ deletion mutant; comp $=\Delta b d t f 1-5$ mutant complemented with a native allele of the Bdtf1 gene $(\Delta b d t f 1: B d t f 1)$.

Table 1. Decreased lesion size on green cabbage caused by three $\Delta b d t f 1$ deletion mutants compared with wild-type Alternaria brassicicola

\begin{tabular}{|c|c|c|c|c|c|}
\hline \multirow[b]{2}{*}{ Mutants } & \multirow[b]{2}{*}{ Degrees of freedom } & \multicolumn{2}{|c|}{ Lesion diameter (mm) } & \multirow[b]{2}{*}{ Decrease in lesion diameter } & \multirow[b]{2}{*}{ Probability ( $P$ value $)$} \\
\hline & & Wild type & Mutant & & \\
\hline$\Delta b d t f 1-5$ & 11 & $9.3 \pm 4.3$ & $3.0 \pm 2.7$ & $68 \%$ & $1.2 \mathrm{E}-05$ \\
\hline$\Delta b d t f 1-9$ & 11 & $11.5 \pm 4.1$ & $3.7 \pm 2.5$ & $67 \%$ & 7.8E-07 \\
\hline$\Delta b d t f 1-12$ & 11 & $11.3 \pm 4.0$ & $3.7 \pm 2.6$ & $67 \%$ & $5.6 \mathrm{E}-06$ \\
\hline$\Delta b d t f 1-5^{\mathrm{a}}$ & 5 & $26.2 \pm 2.4$ & $9.8 \pm 3.0$ & $62 \%$ & $1.4 \mathrm{E}-06$ \\
\hline$\Delta b d t f 1-5$ & 11 & $7.1 \pm 3.0^{\mathrm{b}}$ & $2.4 \pm 0.7$ & $66 \%$ & $2.0 \mathrm{E}-04$ \\
\hline
\end{tabular}

${ }^{a}$ Pathogenicity assay results on wounded plants.

${ }^{\mathrm{b}}$ Diameter of lesions caused by the complemented mutant $\Delta b d t f 1-5: B d t f 1$.

Table 2. Decreased lesion size on five Brassica species caused by the $\Delta$ bdtf1-5 mutant compared to wild-type Alternaria brassicicola

\begin{tabular}{|c|c|c|c|c|c|}
\hline \multirow[b]{2}{*}{ Plant } & \multirow[b]{2}{*}{ d.f. $^{a}$} & \multicolumn{2}{|c|}{ Lesion diameter (mm) } & \multirow[b]{2}{*}{ Decrease in lesion diameter } & \multirow[b]{2}{*}{$P$ value $^{\mathrm{a}}$} \\
\hline & & Wild type & $\Delta b d t f 1-5$ & & \\
\hline Green mustard 'Homiz' (Brassica juncea) & 6 & $16.1 \pm 1.5$ & $3.2 \pm 1.2$ & $80 \%$ & $3.6 \mathrm{E}-06$ \\
\hline Green mustard 'Pizzo' (Brassica juncea)' & 6 & $16.2 \pm 1.7$ & $2.2 \pm 0.7$ & $86 \%$ & $3.5 \mathrm{E}-07$ \\
\hline Cauliflower (Brassica oleracea var. botrytis) & 4 & $6.4 \pm 4.3$ & $1.2 \pm 1.0$ & $81 \%$ & 0.065 \\
\hline Chinese cabbage (Brassica rapa var. pekinensis) & 4 & $5.8 \pm 2.2$ & $1.6 \pm 0.8$ & $72 \%$ & 0.001 \\
\hline Broccoli (Brassica oleracea) & 4 & $11.8 \pm 0.5$ & $1.3 \pm 0.9$ & $89 \%$ & $2.4 \mathrm{E}-04$ \\
\hline
\end{tabular}

a d.f. $=$ degrees of freedom; $P$ value $=$ probability . 
of water produced a primary lesion that did not expand beyond the inoculation site. When pad3 plants were spot-inoculated with 2,000 conidia in $10 \mu \mathrm{l}$ of water, lesions expanded beyond the initial inoculation sites in 2 to 3 days. The lesions caused by the $\Delta b d t f l$ strains and wild-type $A$. brassicicola were similar in size (Table 3; Supplementary Fig. 1).

\section{No difference in colony growth under stress.}

There was no apparent difference between the mutant strains and wild-type A. brassicicola in the rate of vegetative growth on potato dextrose agar (PDA) containing $\mathrm{NaCl}$, sorbitol, $\mathrm{H}_{2} \mathrm{O}_{2}$, menadione, caffeine, or calcofluor white, when mycelial plugs were used (Fig. 3). The effective concentration of each chemical that reduced mycelial growth by $50 \%$ (effective concentrations causing $50 \%$ reduction $\left[\mathrm{EC}_{50}\right]$ ) was identical between the mutant and wild type (Table 4). The size of colonies was also similar between the mutant and the wild type when conidia were inoculated on PDA plates containing each chemical (Supplementary Fig. 2). In addition, the length of germ tubes was similar between the wild type and mutants on the surface of host plants during early pathogenesis (Table 5).

\section{Effect of brassinin on germination.}

An important difference between Brassica species and Arabidopsis thaliana is the presence of the phytoalexin brassinin
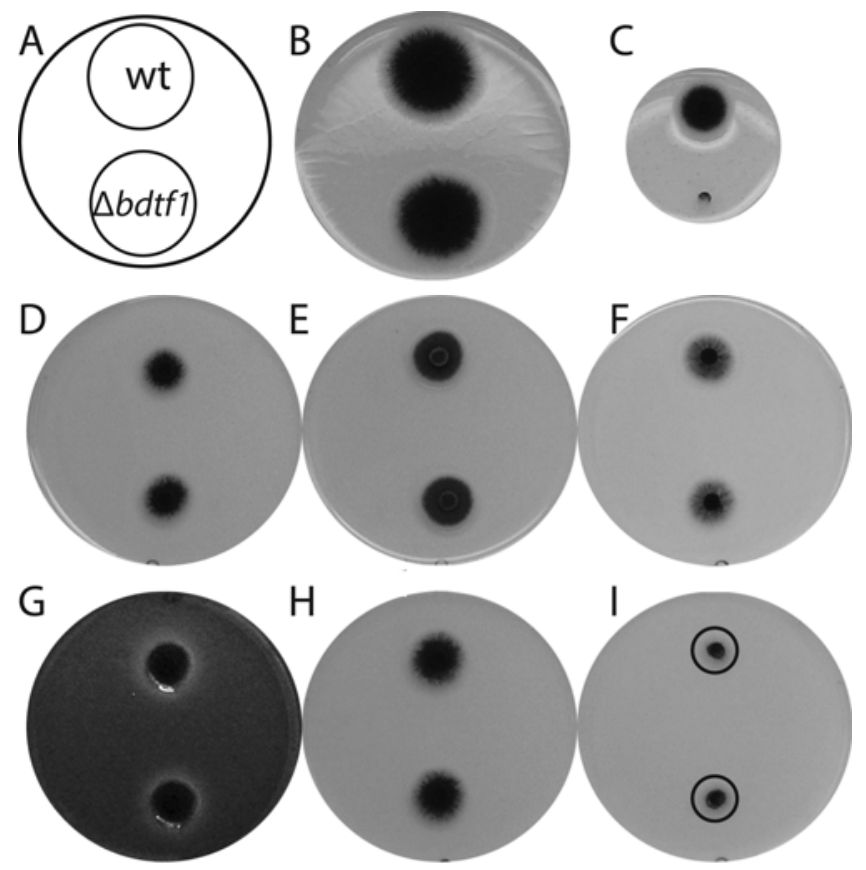

Fig. 3. Comparisons of fungal colony growth on potato dextrose agar at concentrations near those causing $50 \%$ reduction $\left(\mathrm{EC}_{50}\right)$ of each compound. $\mathbf{A}$, Location of inocula, B, no additive, $\mathbf{C}, 0.2 \mathrm{mM}$ brassinin. The black dot at the lower side shows the $\Delta b d t f l$ disk initially transferred. $\mathbf{D}, \mathrm{H}_{2} \mathrm{O}_{2}(12 \mathrm{mM})$, E, $1 \mathrm{mM}$ menadione, F, $2 \mathrm{M}$ sorbitol, G, $100 \mathrm{mg} / \mathrm{ml}$ calcofluor white, H, 4 $\mathrm{mM}$ caffeine, and $\mathbf{I}, 1 \mathrm{M} \mathrm{NaCl}$. Pictures were taken $80 \mathrm{~h}$ postinoculation. in Brassica plants. Therefore, we compared the effects of brassinin on germination over a period of $48 \mathrm{~h}$ after spores were inoculated on PDA containing brassinin. In control experiments on plain PDA and on PDA containing $0.05 \%$ dimethyl sulfoxide (DMSO) (Fig. 4, top panel), germination of all mutants and wild-type conidia was about $100 \%$ at $4 \mathrm{~h}$ postinoculation (hpi). In the presence of $0.1 \mathrm{mM}$ brassinin, germination of both the $\Delta b d t f l$ mutants and the wild type was delayed about $4 \mathrm{~h}$ compared with germination on plain PDA and PDA plus DMSO. In the presence of $0.2 \mathrm{mM}$ brassinin, germination of the wild type was delayed approximately $8 \mathrm{~h}$ and the $\Delta b d t f 1$ mutants did not germinate within the experimental period of $48 \mathrm{~h}$ (Fig. 4 , bottom panel) and up to 6 days (Fig. 5). We also examined the effect of brassinin on conidial germination in $10 \mu$ l of water on microscope slides (Table 4). The $\mathrm{EC}_{50}$ for the wild-type conidia was between 200 and $250 \mu \mathrm{M}$. In comparison, the $\mathrm{EC}_{50}$ for $\Delta b d t f 1-5$ was between 100 and $125 \mu \mathrm{M}$. The germination rate of mutant conidia was approximately $100 \%$ in $100 \mu \mathrm{M}$ and approximately $25 \%$ in $125 \mu \mathrm{M}$ of brassinin.

\section{Effect of brassinin on colony growth.}

We compared colony growth of the $\Delta b d t f 1-5$ and $\Delta b d t f 1-9$ mutant strains, a complemented mutant ( $\Delta b d t f 1-5: B d t f 1)$, and wild-type $A$. brassicicola growing on plain PDA and PDA plus DMSO after the inoculation of spores. All colonies grew similarly on plain PDA and PDA plus DMSO for the six days of the test (Fig. 5A). On PDA with $0.1 \mathrm{mM}$ brassinin, colony diameter of the mutants was 40 to $59 \%$ smaller than that of the wild type (Fig. 5B and C). On PDA with $0.2 \mathrm{mM}$ brassinin, the $\Delta b d t f l$ mutants failed to germinate and form colonies until 6 days postinoculation (dpi) (Fig. 5A to $\mathrm{C}$ ). When the ungerminated mutant conidia from PDA plus $0.2 \mathrm{mM}$ brassinin were transferred to plain PDA, they germinated and formed colonies. Delayed germination could affect the calculation of colony growth. Therefore, we measured the effect of brassinin on hyphal growth of colonies on PDA inoculated with mycelial plugs. The $\mathrm{EC}_{50}$ of brassinin for the growth of the wild-type colony was $2 \mathrm{mM}$. In comparison, the $\mathrm{EC}_{50}$ of brassinin for the $\Delta b d t f 1-5$ colony was $93.8 \mu \mathrm{M}$ (Table 4).

Table 4. Effective concentration causing $50 \%$ reduction $\left(\mathrm{EC}_{50}\right)$ values for wild-type Alternaria brassicicola and its $\Delta b d t f 1$ mutant

\begin{tabular}{lll}
\hline Compound & Wild type & Dbdtfl \\
\hline Brassinin $^{\mathrm{a}}$ & $200-250 \mu \mathrm{M}$ & $100-125 \mu \mathrm{M}$ \\
Brassinin $^{\mathrm{b}}$ & $2.0 \pm 0.1 \mathrm{mM}$ & $93.8 \pm 6.7 \mu \mathrm{M}$ \\
Menadion $^{\mathrm{b}}$ & $1.05 \pm 0.01 \mathrm{mM}$ & $1.05 \pm 0.01 \mathrm{mM}$ \\
Sorbitol $^{\mathrm{b}}$ & $1.07 \pm 0.01 \mathrm{M}$ & $1.07 \pm 0.01 \mathrm{M}$ \\
$\mathrm{Caffeine}^{\mathrm{b}}$ & $4.82 \pm 0.01 \mathrm{mM}$ & $4.82 \pm 0.01 \mathrm{mM}$ \\
$\mathrm{H}_{2} \mathrm{O}_{2}{ }^{\mathrm{b}}$ & $12.29 \pm 0.01 \mathrm{mM}$ & $12.29 \pm 0.01 \mathrm{mM}$ \\
$\mathrm{NaCl}^{\mathrm{b}}$ & $0.80 \pm 0.01 \mathrm{M}$ & $0.80 \pm 0.01 \mathrm{M}$ \\
\hline
\end{tabular}

${ }^{a}$ Germination rates were $>80 \%$ at the lower concentration and $<25 \%$ at the upper concentration of brassinin in water.

${ }^{b}$ Colony growth experiments were performed with mycelial plugs on potato dextrose agar plates. Numbers represent mean \pm standard deviation.

Table 3. Similarity of virulence among wild-type Alternaria brassicicola, mutant $\Delta$ bdtf1-5, and its complemented mutant on Arabidopsis thaliana (Col-0)

\begin{tabular}{|c|c|c|c|c|c|c|c|}
\hline \multirow[b]{2}{*}{ Host plants } & \multirow[b]{2}{*}{ No. } & \multicolumn{3}{|c|}{ Lesion score } & \multirow[b]{2}{*}{$F$ value } & \multirow[b]{2}{*}{$P$ value } & \multirow[b]{2}{*}{$F$ critical } \\
\hline & & A. brassicicola & Mutant $\Delta b d t f 1-5$ & Complemented mutant & & & \\
\hline pad3 & 10 & $13.9 \pm 1.6^{\mathrm{a}}$ & $14.1 \pm 2.4^{\mathrm{a}}$ & - & - & 0.86 & \\
\hline Wild-type Arabidopsis thaliana (Col-0) & 6 & $5.0 \pm 1.0^{\mathrm{b}}$ & $6.0 \pm 1.7^{b}$ & $5.3 \pm 1.2^{\mathrm{b}}$ & 0.44 & 0.67 & 5.14 \\
\hline Wild-type Arabidopsis thaliana (Col-0) & 6 & $20.1 \pm 6.6^{\mathrm{c}}$ & $24.0 \pm 6.6^{\mathrm{c}}$ & $22.8 \pm 6.9^{c}$ & 1.07 & 0.36 & 3.3 \\
\hline
\end{tabular}

\footnotetext{
${ }^{a}$ Lesion diameter (mm).

$\mathrm{b}$ Number of dead leaves.

c Number of lesions.
} 
Effect of brassinin on mycelial growth.

We also tested the effect of brassinin on fungal growth using mycelia harvested from broth containing $1 \%$ glucose and $0.5 \%$ yeast extract (GYEB). We compared the growth of $\Delta b d t f 1-5, \Delta b d t f 1-9$, and wild-type A. brassicicola in fresh GYEB with and without brassinin. Dry weight of wild-type mycelia was $10 \%$ less in the presence of $0.1 \mathrm{mM}$ brassinin and $20 \%$ less in the presence of $0.2 \mathrm{mM}$ brassinin than in plain GYEB (Fig. 6). However, mycelial dry weight of the $\Delta b d t f 1-5$ and $\Delta b d t f l-9$ strains was reduced approximately $70 \%$ (degree of freedom $=5, \mathrm{P}<0.01$ ) in the presence of $0.1 \mathrm{mM}$ brassinin (Fig. 6). In multiple experiments with variable amounts of mycelium, $\Delta b d t f 1-5$ and $\Delta b d t f 1-9$ mutant strains showed no growth in GYEB containing $0.2 \mathrm{mM}$ brassinin. Mycelia inhibited by brassinin resumed growth when transferred to plain PDA or GYEB. It was notable that mutant growth was about $20 \%$ greater than the wild type $(P<0.05)$ in GYEB with $0.05 \%$ DMSO (Fig. 6).

Table 5. Vegetative growth of the $\Delta b d t f 1-5$ mutant and wild-type Alternaria brassicicola on green cabbage (Brassica oleracea)

\begin{tabular}{|c|c|c|c|c|}
\hline \multirow[b]{2}{*}{ Time (h postinoculation) } & \multirow[b]{2}{*}{ Degrees of freedom } & \multicolumn{2}{|c|}{ Length of hyphae (mm) } & \multirow[b]{2}{*}{ Probability ( $P$ value $)$} \\
\hline & & Wild type & Mutant & \\
\hline 12 & 16 & $64 \pm 43$ & $78 \pm 36$ & 0.31 \\
\hline 24 & 150 & $118 \pm 91$ & $105 \pm 69$ & 0.16 \\
\hline 48 & 161 & $139 \pm 145$ & $109 \pm 63$ & 0.14 \\
\hline
\end{tabular}
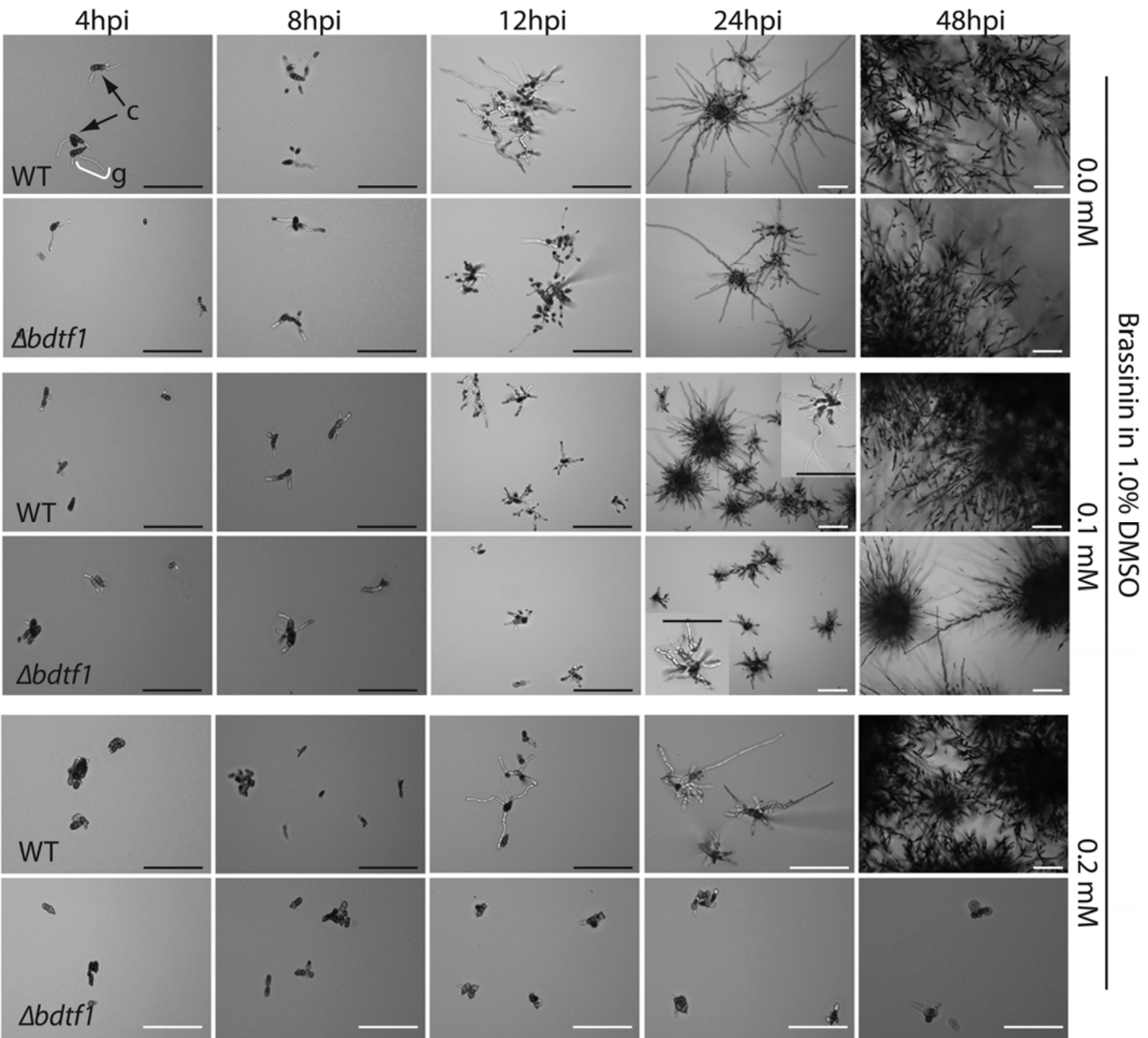

Fig. 4. Effect of brassinin on germination and vegetative growth. Each image displays germination and growth of the $\Delta b d t f 1-5$ mutant or wild-type Alternaria brassicicola on potato dextrose agar (PDA) containing various concentrations of brassinin. Two conidia (c) and a germ tube (g) are marked in the first picture. $\mathrm{hpi}=\mathrm{h}$ postinoculation, $\mathrm{wt}=$ wild-type Alternaria brassicicola, $\Delta b d t f 1=$ deletion mutant of the $B d t f 1$ gene, DMSO $=$ dimethyl sulfoxide. Scale bars $=100$ micrometers. 


\section{Expression of $B d t f 1$ and $B H A b$.}

Bdtfl was important for pathogenesis in Brassica spp. (Fig. 2 ) and for mycelial growth in the presence of brassinin (Figs. 3 and 6). We examined the expression pattern of the Bdtfl gene during parasitic and saprophytic growth, to determine the possible effects of brassinin on its expression. Bdtfl transcripts

A

A
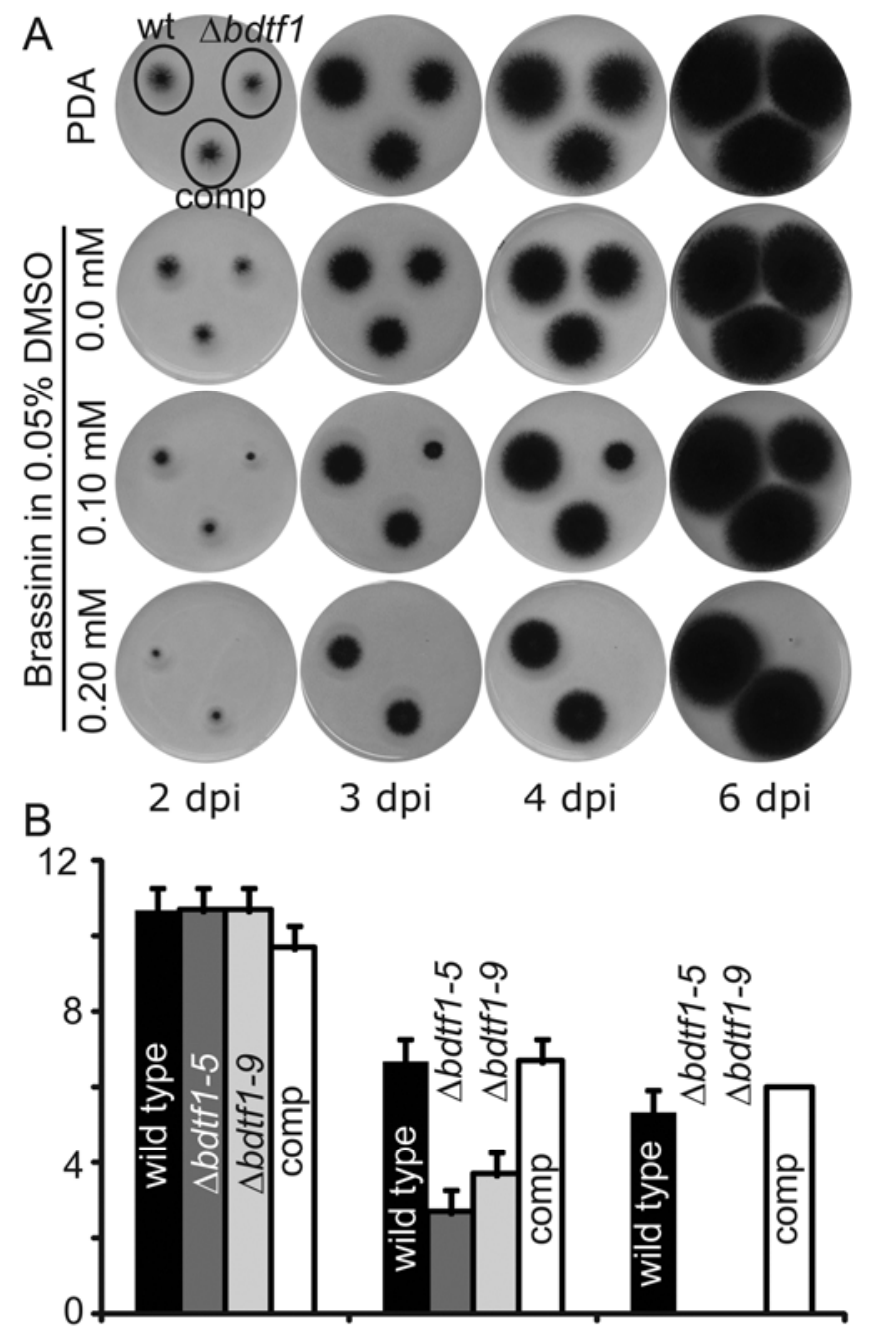

$0 \mathrm{mM}$

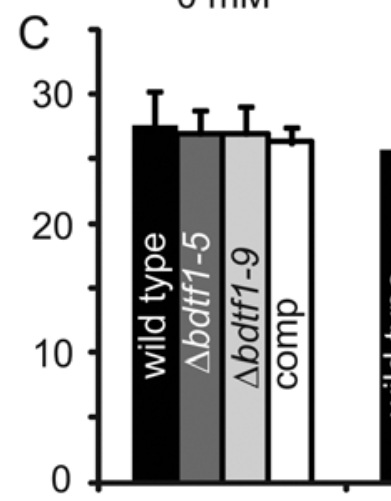

$0 \mathrm{mM}$

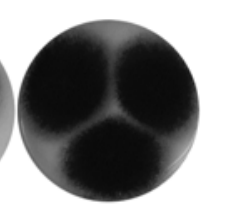

$6 \mathrm{dpi}$ 
sicicola was $2.0 \mathrm{mM}$ (Table 4). In comparison, the $\mathrm{EC}_{50}$ value for mycelial growth of the mutant was less than $0.1 \mathrm{mM}$. The $\mathrm{EC}_{50}$ value for germination of the mutant was only twofold lower than that of the wild type (Table 4). Mutant conidia that did not germinate for 6 days in concentrations of 0.2 to $4 \mathrm{mM}$ brassinin germinated and grew when transferred to plain PDA (data not shown). Similarly, mycelial growth arrested in the presence of $0.2 \mathrm{mM}$ brassinin resumed growth when transferred to brassinin-free GYEB. This regrowth suggested that brassinin was fungistatic not fungicidal at this concentration.

\section{Cause of reduction in virulence of $\Delta b d t f 1$ mutants.}

The average diameter of lesions caused by $\Delta b d t f l$ mutants compared with the wild type was greatly reduced on all Brassica species tested (Fig. 2; Tables 1 and 2). We excluded defects in development as the cause of reduced virulence in the $\Delta b d t f 1$ mutants because they were indistinguishable from the wild type in germination and vegetative growth on PDA. Furthermore, we can exclude the possibility of defects in the integrity of the cell wall or cell membrane, osmoregulation, and response to oxygen stress as the cause of the reduced virulence in the $\Delta b d t f l$ mutants. The $\Delta b d t f l$ mutant strains and wild-type $A$. brassicicola were equally resistant to chemicals affecting the cell wall and osmolarity, such as calcofluor white, caffeine, $\mathrm{NaCl}$, and sorbitol (Fig. 3).

We speculate that the cause of the reduced virulence was associated with the decreased ability of $\Delta b d t f 1$ mutant strains to detoxify brassinin. This explanation is supported by three lines of evidence. First, virulence of the mutants was reduced on Brassica species (Table 2) but not on Arabidopsis thaliana (Table 3). This is consistent with the production of brassinin by most Brassica species but not by Arabidopsis thaliana, which produces camalexin (Pedras et al. 2011a). Second, $\Delta b d t f 1$ mutants produced smaller lesions than the wild type on brassicaceous plants, even when inoculated on wounded tissue (Fig. 2; Table 1). Wounding generally makes a host more vulnerable to a pathogen by allowing easier entry. For example, the nonpathogenic mutants $\Delta a b s t e 12$ and $\Delta a b n i k 1$ of A. brassicicola were able to actively colonize host plants when inoculated on wounded leaves (Cho et al. 2009). In contrast, a phytoalexinsensitive strain of Botrytis cinerea was weakly virulent on wounded tissues (Chassot et al. 2008). It is of note that the phytoalexin camalexin is rapidly induced by wounding (Kishimoto
2006) or that wounding primes the plant for a faster production of camalexin following inoculation with Botrytis cinerea (Chassot et al. 2008). The wounding of Brassica species might have induced brassinin at the inoculation site, inhibiting

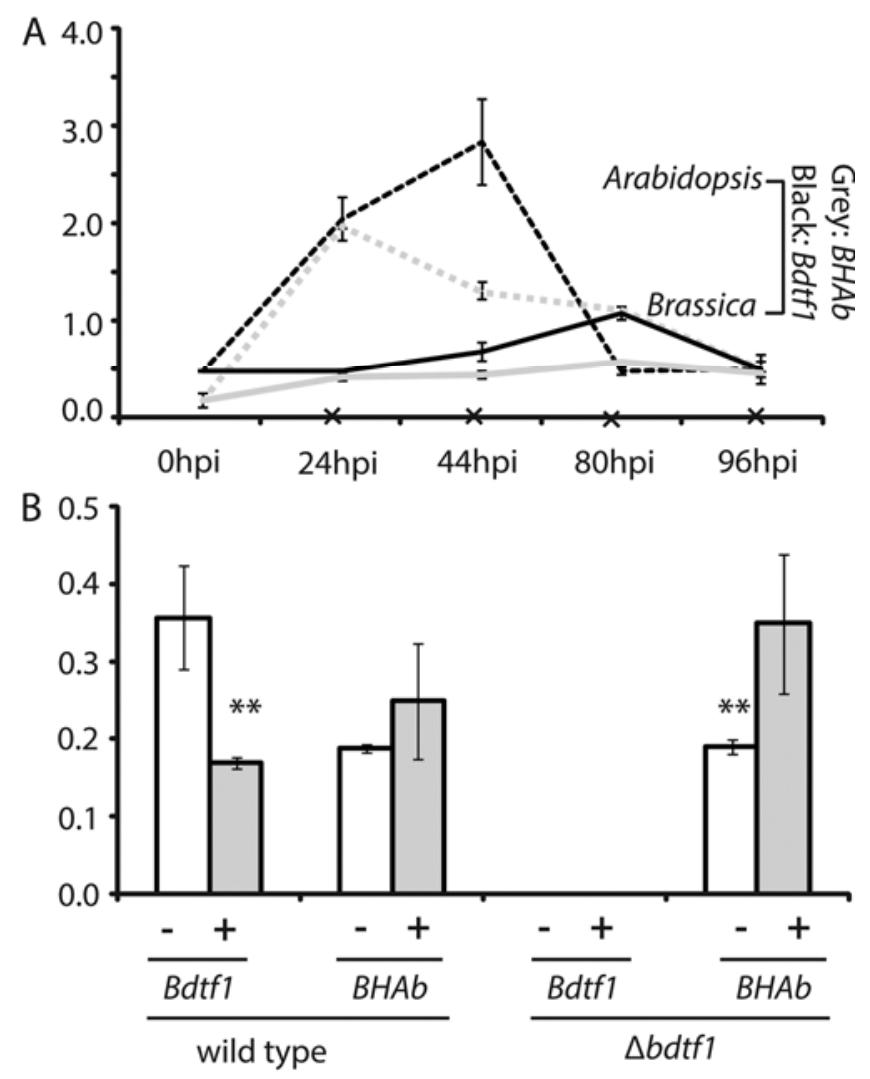

Fig. 7. Expression of the Bdtf1 and $B H A b$ genes in Alternaria brassicicola. A, Relative amount of transcripts in wild-type A. brassicicola during pathogenesis on Arabidopsis thaliana (dashed lines) and Brassica oleracea (solid line). Black lines indicate Bdtfl and gray lines indicate $B H A b$. "X" marks on the $x$ axis indicate $B d t f l$ expression in $\Delta b d t f l$ mutant. $\mathbf{B}$, Relative amounts of transcripts during growth in glucose-yeast-extract broth in the presence $(+)$ and absence (-) of $0.1 \mathrm{mM}$ brassinin. The $y$ axis is the percentile of transcripts for each gene compared with the housekeeping gene, elongation factor $1-\alpha$. Error bars indicate standard deviation. ** indicate $P<0.01$.
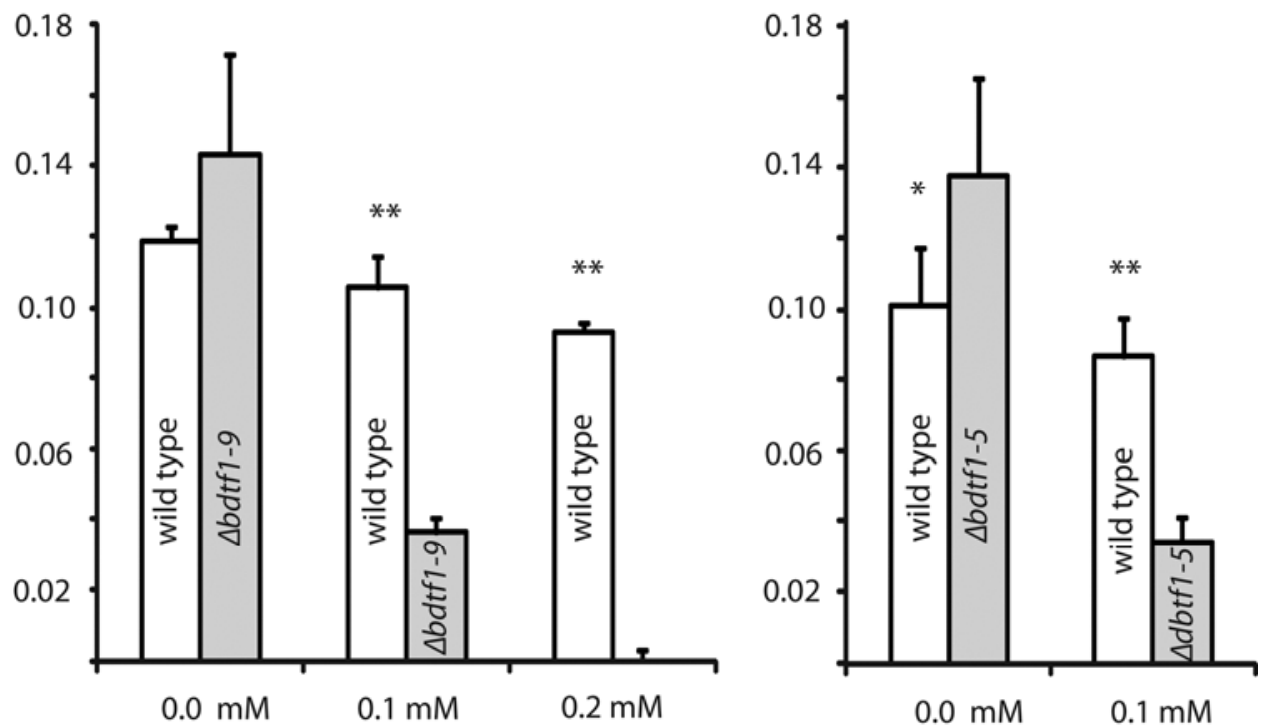

Fig. 6. Effect of brassinin on growth of the $\Delta b d t f 1$ mutants in a liquid medium; $y$ axes show mean dry weight (grams) of mycelia grown in $1 \%$ glucose and $0.5 \%$ yeast extract broth for $24 \mathrm{~h}$. Each chart shows results of the $\Delta b d t f 1-5$ (right) and $\Delta b d t f 1-9$ (left) mutant strains compared with wild-type Alternaria brassicicola. Boxes and bars indicate mean and standard deviation, respectively. ${ }^{*}=(P<0.05)$ and $* *=(P<0.01)$. 
mycelial growth and resulting in smaller lesions. Finally, vegetative growth of the mutants was severely affected in the presence of brassinin (Figs. 3 and 6; Table 4). Mutants failed to detoxify or inefficiently detoxified brassinin, while it was efficiently detoxified by wild-type $A$. brassicicola (Figs. 8 to 10). The induction of brassinin probably occurs after initial colonization, around $24 \mathrm{hpi}$, as in Brassica juncea (Pedras et al. $2009 \mathrm{~b})$. Its presence affects hyphal growth and virulence of the pathogen. Our results provide additional evidence that brassinin is an important phytoalexin in Brassica spp. and that brassinin

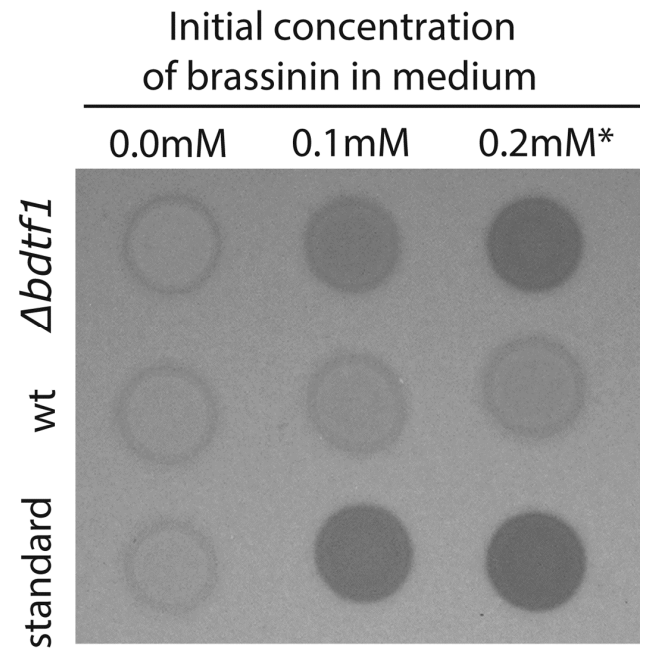

Fig. 8. Reduced degradation of brassinin by $\Delta b d t f l$ during mycelial growth. Thin layer chromatography showing brassinin concentration; spot intensity correlates to the amount of indolyl compounds, including brassinin. detoxification is necessary for successful pathogenesis by the necrotrophic fungus $A$. brassicicola.

Importance of $B d t f 1$ in brassinin detoxification.

The Bdtfl gene was expressed in the conidia of wild-type $A$. brassicicola harvested from 5- to 7-day-old PDA plates, in mycelia grown in a nutrient-rich medium, and in the mycelia infecting host plants (Fig. 7). The level of Bdtfl transcripts might have been maintained so that this parasitic fungus could quickly respond to phytoalexins. This activity, however, may have diverted energy from growth. This could explain why mutants that did not express the gene grew slightly faster than the wild type under favorable conditions, such as the nutrientrich GYEB medium without brassinin (Fig. 6). In contrast, the $\Delta b d t f 1$ mutants were unable to detoxify brassinin (Figs. 9 and 10) and grew much more slowly than the wild type or stopped growing in the presence of brassinin (Fig. 4 to 6). Our data provide strong evidence that inefficient detoxification of brassinin caused the slow vegetative growth. The ability of plantpathogenic fungi to detoxify plant defense compounds is an important determinant of their virulence (Coleman et al. 2011; Schafer et al. 1989).

Brassinin is an important phytoalexin in Brassica species. $B d t f 1$ is essential for the detoxification of brassinin and it probably induces genes encoding brassinin-digesting enzymes. Brassinin can be detected with UV light at wavelengths of 300, 254 , and $220 \mathrm{~nm}$ because of the presence of indolyl groups. $\mathrm{BHAb}$ is a brassinin-detoxification enzyme in A. brassicicola. It hydrolyzes brassinin, producing two indolyl compounds, 3-indolmethanamine and $\mathrm{N}^{\prime}$-acetyl-3-indolmethanamine (Pedras et al. 2009a). These intermediate products are further metabolized to undetermined compounds. However, neither of these intermediate products was detected in this study (Fig. 9). It is
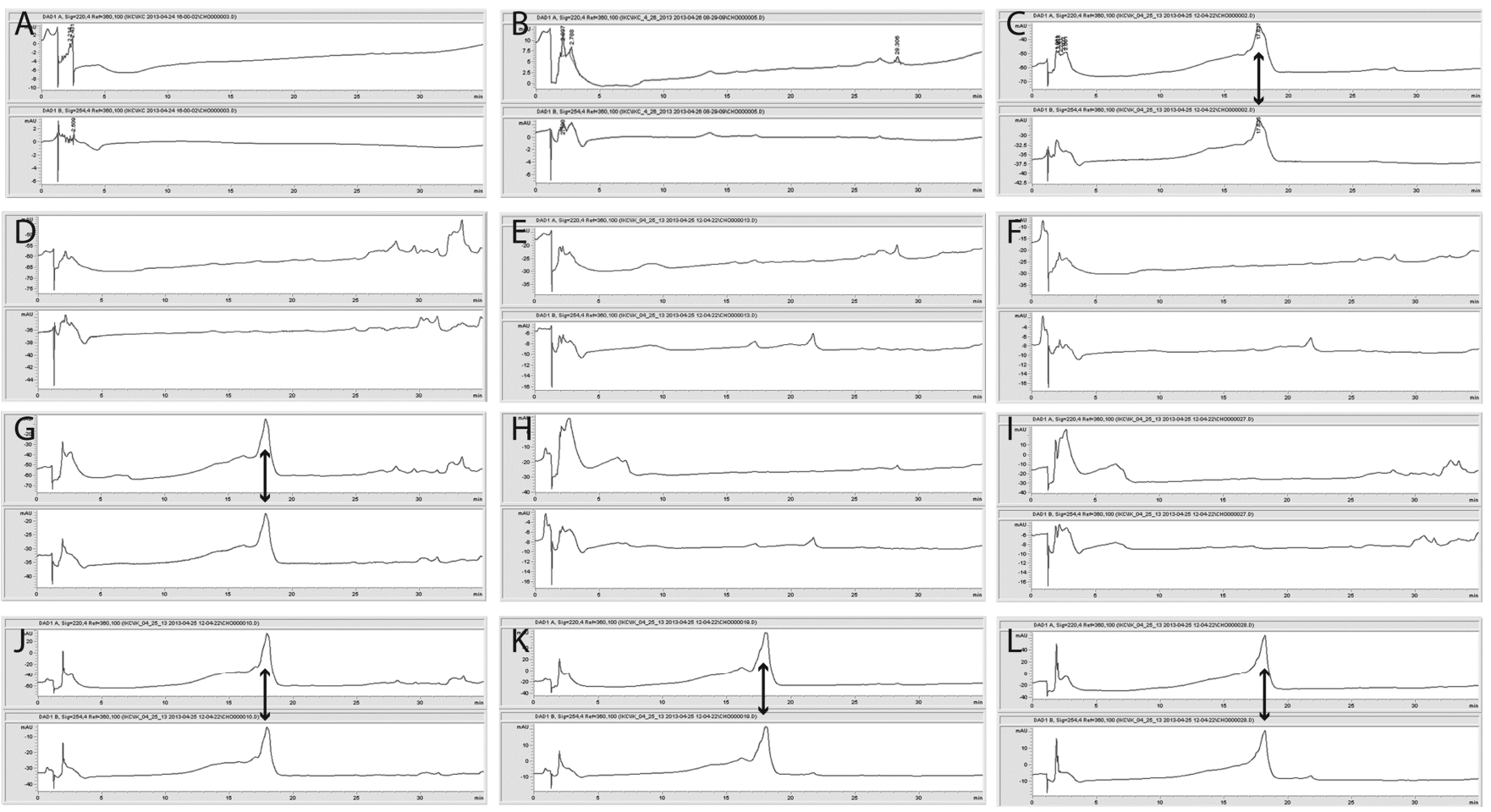

Fig. 9. Brassinin conversion during liquid culture of Alternaria brassicicola. Shown are chromatograms produced with high pressure liquid chromatography (HPLC)-diode array detection. Upper and lower panels show HPLC chromatograms of brassinin that were detected at 220 and 254 nm, respectively. Arrows indicate brassinin peaks. A, Solvent control, B, fungal medium control, C, fungal medium with brassinin. The data show brassinin profiles extracted from culture medium with: D, wild type without brassinin 4 h postinoculation (hpi), E, wild type without brassinin 8 hpi, F, Wild type without brassinin 24 hpi, G, wild type with $0.2 \mathrm{mM}$ brassinin 4 hpi, $\mathbf{H}$, wild type with $0.2 \mathrm{mM}$ brassinin 8 hpi, I, wild type with $0.2 \mathrm{mM}$ brassinin 24 hpi, J, $\Delta b d t f 1$ mutant with $0.2 \mathrm{mM}$ brassinin 4 hpi, K, $\Delta b d t f 1$ mutant with $0.2 \mathrm{mM}$ brassinin $8 \mathrm{hpi}$, and $\mathbf{L}, \Delta b d t f 1$ mutant with $0.2 \mathrm{mM}$ brassinin 24 hpi. 
of note that the intermediate indolyl compounds were produced during the growth of wild-type A. brassicicola in a minimal medium. In addition, camalexin or 3-phenylindole was used for the induction of BHAb activities in A. brassicicola (Pedras et al. 2009a). Notably, BHAb transcripts reached their highest level at $24 \mathrm{hpi}$ and remained mildly elevated until $80 \mathrm{hpi}$, during the infection of Arabidopsis thaliana (Fig. 7A). The elevated expression might be caused by camalexin, which accumulates in Arabidopsis thaliana in response to pathogen infection (Glazebrook and Ausubel 1994). In comparison, we used a nutrient-rich medium to enhance fungal growth without the $\mathrm{BHAb}$-inducing agents. Under our experimental conditions, expression of the $B H A b$ gene was very low in the $\Delta b d t f l \mathrm{mu}-$ tant and wild-type $A$. brassicicola, both with and without brassinin (Fig. 7B). We speculate that the low expression level of $B H A b$ gene in vitro under our test conditions caused inefficient hydrolysis of brassinin. Thus, the intermediate products of brassinin did not accumulate at detectable levels during the 24-h growth of either the wild type or mutant strains. For the reasons described above, we do not think that $B H A b$ is responsible for the conversion of brassinin to the unknown products.

Although it was not addressed in this study, we anticipate that $\Delta b d t f 1$ mutants are sensitive to other brassinin-derived phytoalexins, such as cyclobrassinin, brassilexin, and spirobrassinin. $B$. juncea accumulates these brassinins derivatives but not brassinin in the $48 \mathrm{~h}$ following infection by $A$. brassicicola (Pedras et al. 2009b). Most of these derivatives have stronger antifungal activities than brassinin against Botrytis cinerea (Pedras et al. 2011b). The large reduction in virulence of the $\Delta b d t f l$ mutants on $B$. juncea (Fig. 2) suggests that brassininderived phytoalexins are effective against $\Delta b d t f l$ mutants and that $\Delta b d t f l$ mutants cannot efficiently detoxify them. The $\Delta b d t f l$ mutant will provide opportunities to identify enzymes that are involved in the detoxification of brassinin and possibly bras- sinin-derived phytoalexins (Pedras and Ahiahonu 2005; Pedras et al. 2009b).

Additional unknown mechanisms to counteract brassinins.

The $\Delta b d t f l$ mutant strains were not killed by exposure to 0.2 to $4 \mathrm{mM}$ brassinin, but germination and mycelial growth were completely inhibited. We suggest that additional mechanisms are necessary for the survival of the mutant in the presence of brassinin. Mutant strains unable to detoxify brassinin may induce other genes to mitigate the effect of brassinin like camalexin induces other genes (Joubert et al. 2011; Sellam et al. 2007b). Both brassinin and camalexin are indolyl phytoalexins that inhibit the growth of wild-type A. brassicicola. Both have considerably more toxic effects on $\Delta a b s l t 2$ mutant strains with defective cell-wall integrity (Joubert et al. 2011). Camalexin causes cell-wall permeability and exposure of $A$. brassicicola to camalexin induces genes associated with the biosynthesis of sterol, sphingolipid, melanin, and the efflux of drugs (Sellam et al. 2007b). These genes are probably important in preserving cell-wall integrity or limiting the intracellular accumulation of phytoalexins. If brassinin affects maintenance of the fungal cell wall and its efflux processes, as implied by Joubert and associates (2011), the $\Delta b d t f 1$ mutants will be useful in identifying the genes associated with cell-wall integrity and drug efflux. In addition, the mutants will be instrumental to determine which specific genes are necessary for the enzymatic detoxification of brassinin to nontoxic compounds.

\section{MATERIALS AND METHODS}

Fungal strains, their transformation, and maintenance.

We used the facultative plant pathogen Alternaria brassicicola (Schweinitz) Wiltshire (ATCC96836) in this study. Growth and maintenance of the fungus and its transformation,

Table 6. Conversion of brassinin during saprophytic growth in glucose yeast extract broth medium measured at 254 and 220 nm absorbance

\begin{tabular}{|c|c|c|c|c|c|c|}
\hline \multirow[b]{2}{*}{ Wavelength/medium } & \multicolumn{3}{|c|}{ Area of absorbance peak for brassinin ${ }^{a}$} & \multicolumn{3}{|c|}{ Relative amount of brassinin $(\%)^{b}$} \\
\hline & 4 hpi $^{\mathrm{c}}$ & 8 hpi & 24 hpi & 4 hpi & 8 hpi & 24 hpi \\
\hline \multicolumn{7}{|l|}{$254 \mathrm{~nm}$} \\
\hline Wild type & $876.0 \pm 269.8$ & BDL & BDL & $54.8 \pm 16.9$ & $\mathrm{NC}$ & $\mathrm{NC}$ \\
\hline$\Delta b d t f 1$ & $1,489.4 \pm 545.3$ & $1,567.5 \pm 185.0$ & $1,311.7 \pm 144.3$ & $93.1 \pm 34.1$ & $98.0 \pm 11.6$ & $82.0 \pm 9.2$ \\
\hline Control & BDL & BDL & BDL & 0 & 0 & 0 \\
\hline \multicolumn{7}{|l|}{$220 \mathrm{~nm}$} \\
\hline Wild type & $3,774.2 \pm 50.2$ & BDL & BDL & $58.2 \pm 0.8$ & $\mathrm{NC}$ & $\mathrm{NC}$ \\
\hline$\Delta b d t f 1$ & $6,483.1$ & $6,136.2 \pm 489.0$ & $5,408.2 \pm 250.7$ & 100 & $94.7 \pm 7.5$ & $83.4 \pm 3.9$ \\
\hline Control & BDL & BDL & BDL & $\mathrm{NC}$ & $\mathrm{NC}$ & $\mathrm{NC}$ \\
\hline
\end{tabular}

${ }^{a}$ Area of peak at the retention time of $17.6 \mathrm{~min}$ in high pressure liquid chromatography-diode array detector shown as mean \pm standard deviation.

${ }^{\mathrm{b}}$ Amount left in the medium compared with the input amount of brassinin. BDL = below detection limit; NC = not calculable.

${ }^{\mathrm{c}} \mathrm{hpi}=\mathrm{h}$ postinoculation.
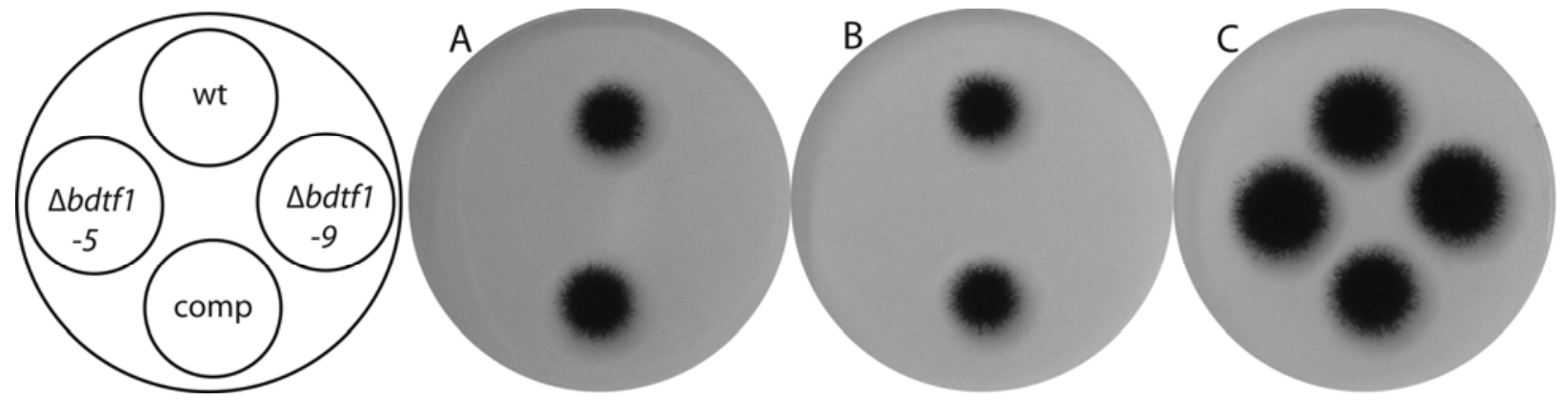

Fig. 10. Loss of brassinin efficacy. Growth of fungal colonies on potato dextrose agar plates containing brassinin and its modified products produced during mycelial growth in a broth medium of $1 \%$ glucose and $0.5 \%$ yeast extract. The products were extracted from broth cultures containing $\mathbf{A}$, no fungus, $\mathbf{B}$, $\Delta b d t f 1-5$, and $\mathbf{C}$, wild-type Alternaria brassicicola. wt $=$ wild-type $A$. brassicicola, $\Delta b d t f 1=$ deletion mutant of Bdtf1, comp $=\Delta b d t f 1-5$ complemented with wild-type allele of Bdtfl ( $\Delta b d t f 1: B d t f 1)$. 
nucleic acid isolation, mutant purification, and mutant verification by Southern hybridization were performed as described previously (Cho et al. 2006, 2012). The wild-type fungus and each of the mutant strains created during this study were purified by two rounds of single-spore isolation. The cultures were maintained as glycerol stock in separate tubes, with one tube used for each assay. The full-length sequence of the gene was retrieved from the genome portal of A. brassicicola at the Joint Genome Institute. The sequence in the coding region was confirmed by manual sequencing. The sequence was deposited in the GenBank database (KC814178) at NCBI. The brassinin hydrolase gene in $A$. brassicicola $(B H A b)$ was mined in the same genome portal using a previously determined amino-acid sequence (Pedras et al. 2009a). Its gene ID in the genome portal is AB00197.1.

\section{Generation of two strains of deletion mutants for Bdtf1.}

We made $B d t f l$ deletion mutants by replacing the gene with a $H y g B$ resistance-gene cassette. To make a construct, the primer set FTF1-DP1 (ACGAGGAAGAGGGAGAGGAG) and FTF1-DP2 (ATCAGTTAACGTCGACCTCGGATCGCGGAA GTTTGTTGAT) and the primer set FTF1-DP5 (GGAACCAGT TAACGTCGACGGTGCTGGCGTTTAACTGGAT) and FTF1DP6 (ACAACTGGTGGGTCTCCAAG) were used respectively to amplify an approximately $1-\mathrm{Kb}$ region at the $5^{\prime}$ and $3^{\prime}$ flanking regions of the targeted locus. Another set of primers, FTF1-DP3 (ATCAACAAACTTCCGCGATCCGAGGTCGAC GTTAACTGAT) and FTF1-DP4 (ATCCAGTTAAACGCCAG CACCGTCGACGTTAACTGGTTCC) was used to amplify the $H y g B$ resistance-gene cassette $(1,436 \mathrm{bp})$ from pCB1636. The final transformation constructs were produced by polymerase chain reaction (PCR) amplification using the mix of products from three reactions as template DNA and two primers, FTF1-DP1 and FTF1-DP6. We also made Bdtf1 deletion mutants expressing green fluorescence and the $\mathrm{Hyg} B$ resistancegene cassette under the control of the Bdtfl gene promoter ( $\Delta b d t f 1: B d t f 1 \mathrm{P}-G F P: H y g B)$. To make the construct, the Bdtfl promoter region and $3^{\prime}$ flanking region were amplified with primer pairs FTF1-DP1 and 2FTF1-GFPc5R (CTCGCCCT TGCTCACCATCTCGATTCGCTGTGTTC) and FTF1-DP5 and FTF1-DP6 respectively. Another set of primers, 3FTF15RcGFPF (GAACACAGCGAATCGAGATGGTGAGCAAGG GCGAG) and FTF1-DP4, were used to amplify the 2,384 bp that covered the coding regions of the GFP and the $H y g B$ resistance-gene cassette from plasmid pCB16G6 (Cho et al. 2006). The amplicons from three reactions were then mixed and were amplified with primer pairs P1 and P6 to make the final construct that was used for transformation of the wild-type strain.

\section{Southern hybridization.}

Southern hybridizations were performed as described previously (Cho et al. 2006), with appropriate modifications. DNA extracted from each transformant was digested with the endonuclease HindIII. The blot was hybridized with three probes and synthesized with a PCR DIG probe synthesis kit according to the manufacturer's manual (Roche Diagnostics, Mannheim, Germany). A gene-specific probe was generated with the primer set FTF1-HybF (TCTCGCCTGTGCATCACTAC) and FTF1HybR (CCTCTAAGCTTGCGGCATAC). The probe for the flanking region was produced with FTF1-DP5 and FTF1-DP6, and the HygB-specific probe was produced with HygIn84 (CTT GGCTGGAGCTAGTGGAG) and HygIn1343 (ATTTGTGTA CGCCCGACAGT).

\section{Complementation of the $\Delta b d t f 1$ mutants.}

The $\Delta b d t f 1-5$ mutant was complemented with the wild-type Bdtfl allele under its native promoter. Two primers, P1 and P6, were used to amplify the 4,722-bp wild-type allele of the BdtfI gene using $A$. brassicicola genomic DNA as a template. The amplified product was used to reintroduce wild-type $B d t f 1$ into the $\Delta b d t f 1-5$ mutant $(\Delta b d t f 1: B d t f l)$. The PCR product included a 1,047-bp 5' flanking region, 2,692-bp complete coding region, and a 983-bp 3' flanking region. This product was used to transform the $\Delta b d t f l-5$ mutant as described previously (Cho et al. 2012). Complemented mutant clones were purified by two rounds of single-spore isolation.

\section{Pathogenicity assays.}

If not otherwise described, we performed most analyses with the $\Delta b d t f 1-5$ and $\Delta b d t f l-9$ mutants. These strains represent each group of mutants whose $B d t f l$ gene was replaced by different constructs. Conidia from 5- to 7-day-old colonies growing on PDA plates were harvested in sterilized water and were washed twice before inoculation. Pathogenicity assays were performed on leaves detached from 5- to 8-week-old green cabbage (Brassica oleracea) plants. The leaves were placed in moist minichambers and were randomly located on a laboratory bench. Pathogenicity assays with oilseed mustard (B. juncea), cauliflower (B. oleracea var. botrytis), broccoli (B. oleracea), and Chinese cabbage ( $B$. rapa var. pekinensis) were performed on 5-week-old whole plants at the same time and under the same conditions using 2,000 conidia in $10 \mu \mathrm{l}$ of water per spot-inoculation as previously described (Cho et al. 2006). Assays on whole plants and calculations of decreased virulence were performed as described previously (Srivastava et al. 2012). The assays were also performed on whole plants of wild-type Arabidopsis thaliana (Col-0) and on its pad3 mutant (Col-0 background) (Zhou et al. 1999). Plants of wild-type Arabidopsis thaliana were spray-inoculated with $5 \times 10^{5}$ conidia per milliliter, and plants of the pad 3 mutants were spot-inoculated with 2,000 conidia in $10 \mu \mathrm{l}$ of water. Wounds were made on host plants by scraping the leaf epidermis with a sterile plastic pipette tip until sap oozed but without rupturing the leaf.

\section{Effect of chemicals on mycelial growth.}

Each fungal strain from glycerol stocks was grown in the dark for 5 days at $25^{\circ} \mathrm{C}$. In order to test for sensitivity to osmotic, oxidative, and parietal stress, mycelial plugs of the wild type and mutant were transferred onto PDA plates containing various chemicals. Each plate contained either $0.75,1,1.25$, or $1.5 \mathrm{M} \mathrm{NaCl} ; 1.5,2$, or $2.5 \mathrm{M}$ sorbitol; $8,10,12,14$, or $20 \mathrm{mM}$ hydrogen peroxide; 50 or $100 \mathrm{mg}$ calcofluor white per milliliter; $0.1,0.2,0.5,1$, or $2 \mathrm{mM}$ menadione (oxidative stress); or $1,2,4,8$, or $10 \mathrm{mM}$ caffeine (parietal stress). Colony diameters were measured 4 dpi. Linear regression curves were used to determine the $\mathrm{EC}_{50}$ in colony growth.

\section{Germination and colony growth assays.}

A lyophilized powder of $100 \mathrm{mg}$ of brassinin (Santa Cruz Biotechnology, CA, U.S.A.) was dissolved in $1 \mathrm{ml}$ of DMSO. Tubes with $250 \mu \mathrm{l}$ of a $100 \mathrm{mg} / \mathrm{ml}$ brassinin solution were stored at $-20^{\circ} \mathrm{C}$, with individual tubes defrosted just before use. To obtain 0.1 and $0.2 \mathrm{mM}$ concentrations of brassinin in PDA, we added, respectively, $12.5 \mu \mathrm{l}$ and $25 \mu \mathrm{l}$ of the solution to $50 \mathrm{ml}$ of PDA cooled to $50^{\circ} \mathrm{C}$. The agar was thoroughly mixed and immediately poured into $80-$ and $150-\mathrm{mm}$ disposable petri plates. After the PDA plus brassinin solidified, conidia of the $\Delta b d t f 1-5$ strain, the complemented mutant, or wild-type A. brassicicola harvested from 5-day-old PDA plates were inoculated onto the agar. Similarly, the PDA containing brassinin was poured onto microscope slides and inoculated with conidia. Spore germination rate and vegetative growth were then measured and recorded daily using a digital camera 
(SZX2; Olympus, St. Joseph, MI, U.S.A.) mounted on a phase contrast microscope (BX41; Olympus).

\section{Effect of brassinin on colony growth.}

Disks $5 \mathrm{~mm}$ in diameter were cut from the margins of colonies grown on PDA for 5 days and were then transferred to PDA supplemented with $0,0.5,1,2$, or $4 \mathrm{mM}$ of brassinin. Colonies were grown in the dark at $25^{\circ} \mathrm{C}$ for $80 \mathrm{~h}$ and their diameters were measured each day. Inhibition of radial growth was calculated for each concentration, using the following formula: $\left[\left(D_{w o}-D_{w}\right) / 2\right] /\left[\left(D_{w o}-5\right) / 2\right] \times 100$, where $D_{\text {wo }}$ and $D_{w}$ are the diameters of colonies grown on PDA without and with brassinin, respectively. The $\mathrm{EC}_{50}$ for mycelial growth was determined by linear regression of the inhibition of radial growth values against the values of the brassinin concentrations.

\section{Effect of brassinin on germination.}

We also examined the effects of brassinin on spore germination of the $\Delta b d t f 1$ mutants and wild-type A. brassicicola. Spore suspensions $\left(2 \times 10^{4}\right.$ spores per milliliter $)$ were prepared in sterile distilled water from 5-day-old PDA cultures. A total of $10 \mu \mathrm{l}$ of the suspension was mixed with brassinin to obtain 31,62 , 100,125 , and $250 \mu \mathrm{M}$ concentrations of brassinin. The suspensions were then transferred to glass microscope slides and placed in petri dishes lined with wet paper towels to keep the relative humidity around $100 \%$. The petri dishes were incubated in the dark at $24^{\circ} \mathrm{C}$ for $24 \mathrm{~h}$. The percentage of spore germination was determined under a microscope. A spore was scored as germinated if the germ-tube length was equal to or greater than the length of the conidium.

\section{Mycelial growth in GYEB medium.}

Fungal mycelia were grown for 2 to 3 days in a GYEB (1\% glucose and $0.5 \%$ yeast extract) medium. The broth was refreshed $16 \mathrm{~h}$ before harvest. We then transferred $0.15 \mathrm{~g}$ of mycelium (equivalent to $0.025 \mathrm{~g}$ dry weight), partially dried by pressing and removing residual medium, to GYEB containing $0.0,0.1$, or $0.2 \mathrm{mM}$ brassinin. The mycelia were cultured at $25^{\circ} \mathrm{C}$ in a shaker-incubator for $24 \mathrm{~h}$ and then harvested. The dry weight of the harvested mycelia was measured after baking at $75^{\circ} \mathrm{C}$ for $48 \mathrm{~h}$.

\section{Quantitative real time PCR.}

RNA was extracted from fungal or fungal-plant mixed tissues using a Plant RNeasy kit (Qiagen, Palo Alto, CA, U.S.A.). During the RNA extraction, DNA was digested with RNasefree DNase following the manufacturer's protocol. A 1- $\mu \mathrm{g}$ sample of total RNA was then transcribed to cDNA in a final volume of $20 \mu \mathrm{l}$, using $50 \mathrm{ng}$ of random pentamers and $200 \mathrm{ng}$ of poly $(\mathrm{T})_{20} \mathrm{~N}$ with Superscript III (Invitrogen, Carlsbad, CA, U.S.A.). Each cDNA was diluted 1:10 and $1 \mu \mathrm{l}$ (cDNA converted from $5 \mathrm{ng}$ of total RNA) was used per reaction. Subsequent quantitative real time PCR reactions were performed in a $20-\mu \mathrm{l}$ volume containing $120 \mathrm{nM}$ of each primer, $1 \mu \mathrm{l}$ of diluted cDNA, and $10 \mu \mathrm{l}$ of FastStart SYBRGreen Master (Roche, Mannheim, Germany). Each reaction was run in triplicate for both the standard and unknown samples. Reactions were run as described previously (Cho et al. 2006). Standard curves were produced with purified amplified DNA products at starting concentrations of $10 \mathrm{pg} / \mu \mathrm{l}, 1 \mathrm{pg} / \mu \mathrm{l}, 100 \mathrm{fg} / \mu \mathrm{l}, 10$ $\mathrm{fg} / \mu \mathrm{l}$, and $1 \mathrm{fg} / \mu \mathrm{l}$. A baseline subtracted curve fit was used to generate standard curve data. Absolute amounts of transcripts were calculated using a correlation coefficient formula generated from the standard curve in each run with length correction by the size of each gene and amplicon. Relative amounts of transcripts for each gene was calculated compared with the housekeeping gene elongation factor $1-\alpha$ by the following formula: [(number of transcripts of a gene)/(number of transcripts of $E f 1-\alpha)] * 100$. Pairs of primers used for $B d T f 1, B H A b$ (AB00197.1), and Ef1- $\alpha$ genes are BdTf1_rtF (GTCAGAGCA TAGCCGACACA) BdTf1_rtR (TGAAGCTTCGGAGGAAA GAG), BHAb_rtF (TTCTGGTGGAGAGGGAGCTA), BHAb_ rtR (GGATCCTGATAGAGCCACCA) and Ef1 $\alpha \_r t F$ (GGGTC CTCGACAAGTTGAA), and Ef1 $\alpha \_r t R$ (GGGAGCGTCAAT AACTGTGA).

\section{Brassinin conversion assay.}

During mycelial growth assays in the presence of brassinin, $2 \mathrm{ml}$ of GYEB was recovered from each culture flask. After removal of the mycelia by centrifugation at $21,854 \times g$ for $5 \mathrm{~min}$, $0.8 \mathrm{ml}$ of GYEB from each culture was transferred to a clean tube and was extracted twice, using $0.8 \mathrm{ml}$ of chloroform for each extraction. The combined chloroform extracts were dried in a Savant Speedvac Concentrator (Fisher Scientific, Pittsburgh, PA, U.S.A.). The pellet was dissolved in $16 \mu \mathrm{l}$ of DMSO and was spotted on a thin layer of silica gel. The relative concentration and integrity of the brassinin were evaluated under UV light before and after separating the compounds. The UV light source was a Foto UV300 DNA transilluminator with an ultraviolet glass filter (Fotodyne Inc, Harland, WI, U.S.A.). The filter transmits a $300-\mathrm{nm}$ range of light, which is optimum for detecting an ethidium bromide-DNA complex. This method was easily implemented in a molecular biology laboratory. Further quantification of the conversion was performed with HPLC-DAD as described in the following section.

\section{HPLC-DAD analysis of brassinin.}

Analyses were carried out on an Agilent 1100 (Agilent, Palo Alto, CA, U.S.A.) equipped with a DAD, a binary pump, an ALS autosampler, and a thermostatted column compartment maintained at $20^{\circ} \mathrm{C}$. A $0.1 \mathrm{mg} / \mathrm{ml}$ stock solution of brassinin was prepared by dissolving $50 \mu \mathrm{l}$ of $100 \mathrm{mg} / \mathrm{ml}$ of brassinin in $50 \mathrm{ml}$ of HPLC-grade acetonitrile (ACN). Different working standards of $0.1,0.5,2,5$, and $10 \mu \mathrm{g} / \mathrm{ml}$ were prepared from the stock solution. The pellets were reconstituted with $100 \mu \mathrm{l}$ of $\mathrm{ACN}$ and were shaken on a pulsing vortex mixer (Fisher Scientific) for $5 \mathrm{~min}$. The solution was then filtered through $0.2 \mu \mathrm{M}$ polyvinylidene diflouride membrane filters (Acrodisc LC13; (Pall corporation; Port Washington, NY, U.S.A.) before injection into the HPLC system. Brassinin was separated from the solution on a C18 column (Luna C18, 100 A5 $\mu \mathrm{M}, 4.6 \times$ $250 \mathrm{~mm}$, GL Sciences Inc., Torrance, CA, U.S.A.). The solvent system provided a gradient from 23 to $100 \% \mathrm{ACN}$ in water for $35 \mathrm{~min}$. The flow rate and injection volume were $1.0 \mathrm{ml} / \mathrm{min}$ and $20 \mu \mathrm{l}$, respectively. The retention time of brassinin at 220 and $254 \mathrm{~nm}$ wavelengths was $17.6 \mathrm{~min}$. All experiments were performed with biological triplicates.

\section{Bioassays of detoxified brassinin.}

The dried extract prepared from the brassinin conversion assays was dissolved in $16 \mu \mathrm{l}$ of DMSO. We added the dissolved pellet to the PDA as described above and tested the germination rate and relative growth of the $\Delta b d t f l$ mutants, complemented mutant, and wild-type A. brassicicola. We measured colony size 4 dpi by averaging three measurements of the colony diameter.

\section{ACKNOWLEDGMENTS}

We thank W. Borth, A. Alvarez, and J. Hu for generously sharing their research equipment; J. Siu and H. Trung for plant production and care; and F. Brooks for a critical reading of the manuscript. This research was supported by HATCH funds to Y. Cho, administered by the College of Tropical Agriculture and Human Resources, University of Hawaii at Manoa, Honolulu, HI, U.S.A. 


\section{LITERATURE CITED}

Ahuja, I., Kissen, R., and Bones, A. M. 2012. Phytoalexins in defense against pathogens. Trend Plant Sci. 17:73-90.

Bateman, A., Coin, L., Durbin, R., Finn, R. D., Hollich, V., Griffiths-Jones, S., Khanna, A., Marshall, M., Moxon, S., Sonnhammer, E. L., Studholme, D. J., Yeats, C., and Eddy, S. R. 2004. The Pfam protein families database. Nucleic Acids Res. 32:D138-141.

Boller, T., and Felix, G. 2009. A renaissance of elicitors: Perception of microbe-associated molecular patterns and danger signals by patternrecognition receptors. Annu. Rev. Plant Biol. 60:379-406.

Chassot, C., Buchala, A., Schoonbeek, H. J., Metraux, J. P., and Lamotte, O. 2008. Wounding of Arabidopsis leaves causes a powerful but transient protection against Botrytis infection. Plant J. 55:555-567.

Cho, Y., Davis, J. W., Kim, K. H., Wang, J., Sun, Q. H., Cramer, R. A. J., and Lawrence, C. B. 2006. A high throughput targeted gene disruption method for Alternaria brassicicola functional genomics using linear minimal element (LME) constructs. Mol. Plant-Microbe Interact. 19:7-15.

Cho, Y., Kim, K.-H., La Rota, M., Scott, D., Santopietro, G., Callihan, M., and Lawrence, C. B. 2009. Identification of virulence factors by high throughput targeted gene deletion of regulatory genes in Alternaria brassicicola. Mol. Microbiol. 72:1316-1333.

Cho, Y., Srivastava, A., Ohm, R. A., Lawrence, C. B., Wang, K. H., Grigoriev, I. V., and Marahatta, S. P. 2012. Transcription factor Amrl induces melanin biosynthesis and suppresses virulence in Alternaria brassicicola. PLoS Pathog. 8:e1002974. Published online.

Cho, Y., Ohm, R. A., Grigoriev, I. V., and Srivastava, A. 2013. Fungalspecific transcription factor $A b P f 2$ activates pathogenicity in Alternaria brassicicola. Plant J. 75:498-514.

Coleman, J. J., Wasmann, C. C., Usami, T., White, G. J., Temporini, E. D., McCluskey, K., and VanEtten, H. D. 2011. Characterization of the gene encoding pisatin demethylase (FoPDA1) in Fusarium oxysporum. Mol. Plant-Microbe Interact. 24:1482-1491.

Glazebrook, J., and Ausubel, F. M. 1994. Isolation of phytoalexin-deficient mutants of Arabidopsis thaliana and characterization of their interactions with bacterial pathogens. Proc. Natl. Acad. Sci. U.S.A. 91:89558959.

Glazebrook, J., Rogers, E. E., and Ausubel, F. M. 1996. Isolation of Arabidopsis mutants with enhanced disease susceptibility by direct screening. Genetics 143:973-982.

Govrin, E. M., and Levine, A. 2002. Infection of Arabidopsis with a necrotrophic pathogen, Botrytis cinerea, elicits various defense responses but does not induce systemic acquired resistance (SAR). Plant Mol. Biol. 48:267-276.

Gust, A. A., Biswas, R., Lenz, H. D., Rauhut, T., Ranf, S., Kemmerling, B., Gotz, F., Glawischnig, E., Lee, J., Felix, G., and Nurnberger, T. 2007. Bacteria-derived peptidoglycans constitute pathogen-associated molecular patterns triggering innate immunity in Arabidopsis. J. Biol. Chem. 282:32338-32348.

Hammerschmidt, R. 1999. PHYTOALEXINS: What have we learned after 60 years? Ann. Rev. Phytopathol. 37:285-306.

Horton, P., and Nakai, K. 1997. Better prediction of protein cellular localization sites with the $\mathrm{k}$ nearest neighbors classifier. Pages 147-152 in: Proceeding of the Fifth InternationalConference on Intelligent Systems for Molecular Biology. T. Gaasterland, P. Karp, K. Karplus, C. Ouzounis, C. Sander, and A. Valencia, eds. American Association for Artificial Intelligence, Halkidiki, Greece.

Jones, J. D., and Dangl, J. L. 2006. The plant immune system. Nature 444:323-329.

Joubert, A., Bataille-Simoneau, N., Campion, C., Guillemette, T., Hudhomme, P., Iacomi-Vasilescu, B., Leroy, T., Pochon, S., Poupard, P., and Simoneau, P. 2011. Cell wall integrity and high osmolarity glycerol pathways are required for adaptation of Alternaria brassicicola to cell wall stress caused by brassicaceous indolic phytoalexins. Cell Microbiol. 13:62-80.

Kishimoto, K., Matsui, K., Ozawa, R., and Takabayashi, J. 2006. Components of C6-aldehyde-induced resistance in Arabidopsis thaliana against a necrotrophic fungal pathogen, Botrytis cinerea. Plant Sci. 170:715-723.
Millet, Y. A., Danna, C. H., Clay, N. K., Songnuan, W., Simon, M. D., Werck-Reichhart, D., and Ausubel, F. M. 2010. Innate immune responses activated in Arabidopsis roots by microbe-associated molecular patterns. Plant Cell 22:973-990.

Okazaki, Y., Isobe, T., Iwata, Y., Matsukawa, T., Matsuda, F., Miyagawa, H., Ishihara, A., Nishioka, T., and Iwamura, H. 2004. Metabolism of avenanthramide phytoalexins in oats. Plant J. 39:560-572.

Pedras, M. S., and Ahiahonu, P. W. 2005. Metabolism and detoxification of phytoalexins and analogs by phytopathogenic fungi. Phytochemistry 66:391-411.

Pedras, M. S., Minic, Z., and Sarma-Mamillapalle, V. K. 2009a. Substrate specificity and inhibition of brassinin hydrolases, detoxifying enzymes from the plant pathogens Leptosphaeria maculans and Alternaria brassicicola. FEBS (Fed. Eur. Biochem. Soc.) J 276:7412-7428.

Pedras, M. S., Chumala, P. B., Jin, W., Islam, M. S., and Hauck, D. W. 2009b. The phytopathogenic fungus Alternaria brassicicola: Phytotoxin production and phytoalexin elicitation. Phytochemistry 70:394-402.

Pedras, M. S., Yaya, E. E., and Glawischnig, E. 2011a. The phytoalexins from cultivated and wild crucifers: Chemistry and biology. Nat. Prod. Rep. 28:1381-1405.

Pedras, M. S., Hossain, S., and Snitynsky, R. B. 2011b. Detoxification of cruciferous phytoalexins in Botrytis cinerea: Spontaneous dimerization of a camalexin metabolite. Phytochemistry 72:199-206.

Rogers, E. E., Glazebrook, J., and Ausubel, F. M. 1996. Mode of action of the Arabidopsis thaliana phytoalexin camalexin and its role in Arabidopsis-pathogen interactions. Mol. Plant-Microbe Interact. 9:748-757.

Schafer, W., Straney, D., Ciuffetti, L., VanEtten, H. D., and Yoder, O. C. 1989. One enzyme makes a fungal pathogen, but not a saprophyte, virulent on a new host plant. Science 246:247-249.

Sellam, A., Iacomi-Vasilescu, B., Hudhomme, P., and Simoneau, P. 2007a. In vitro antifungal activity of brassinin, camalexin and two isothiocyanates against the crucifer pathogens Alternaria brassicicola and Alternaria brassicae. Plant Pathol. 56:296-301.

Sellam, A., Dongo, A., Guillemette, T., Hudhomme, P., and Simoneau, P. 2007b. Transcriptional responses to exposure to the brassicaceous defence metabolites camalexin and allyl-isothiocyanate in the necrotrophic fungus Alternaria brassicicola. Mol. Plant Pathol. 8:195-208.

Shlezinger, N., Minz, A., Gur, Y., Hatam, I., Dagdas, Y. F., Talbot, N. J., and Sharon, A. 2011. Anti-apoptotic machinery protects the necrotrophic fungus Botrytis cinerea from host-induced apoptotic-like cell death during plant infection. PLoS Pathog. 7:e1002185. Published online.

Srivastava, A., Ohm, R. A., Oxiles, L., Brooks, F., Lawrence, C. B., Grigoriev, I. V., and Cho, Y. 2012. A zinc-finger-family transcription factor, $A b V f 19$, is required for the induction of a gene subset important for virulence in Alternaria brassicicola. Mol. Plant-Microbe Interact. 25:443-452.

Tada, Y., Kusaka, K., Betsuyaku, S., Shinogi, T., Sakamoto, M., Ohura, Y., Hata, S., Mori, T., Tosa, Y., and Mayama, S. 2005. Victorin triggers programmed cell death and the defense response via interaction with a cell surface mediator. Plant Cell Physiol. 46:1787-1798.

Takasugi, M., Katsui, N., and Shirata, A. 1986. Isolation of three novel sulphur-containing phytoalexins from the chinese cabbage Brassica campestris L. ssp. pekinensis (cruciferae). J. Chem. Soc. Chem. Commun. 14:1077-1078.

Vishwanath, S.J.K., Singh, M.P., and Awasthi, R.P. 1999. Induction of resistance in mustard (Brassica juncea) against Alternaria black spot with an avirulent Alternaria brassicae isolate-D. Eur. J. Plant Pathol. 105:217-220.

Zhou, N., Tootle, T. L., and Glazebrook, J. 1999. Arabidopsis PAD3, a gene required for camalexin biosynthesis, encodes a putative cytochrome P450 monooxygenase. Plant Cell 11:2419-2428.

\section{AUTHOR-RECOMMENDED INTERNET RESOURCES}

Joint Genome Institute Genome Portal: genome.jgi.doe.gov

The National Center for Biotechnology Information Genome database: www.ncbi.nlm.nih.gov/genome 